DOI 10.18551/rjoas.2019-01.17

\title{
SANITATION, DRINKING WATER ACCESS AND DIARRHEA IN INDONESIA
}

\author{
Wahyudi Arief \\ Department of Economics, Economic and Business Faculty, University of Indonesia, \\ Depok, Indonesia \\ E-mail: ariefwyd11@gmail.com \\ Patunru Arianto Arif \\ The Arndt-Corden Department of Economics, Australian National University, \\ Canberra, Australia \\ E-mail: arianto.paturnu@anu.edu.au
}

\begin{abstract}
Diarrhea remains one of the main causes of death of young children, particularly in developing countries. Poor water and sanitation are the main drivers of this disease. Indonesia still faces problems in providing improved drinking water and proper sanitation access for all communities. The Government of Indonesia has pledged to meet the target of SDGs in sanitation and clean water in 2019 with 'universal access'. This study objective to examine whether the relationship between unimproved sanitation, unimproved water and diarrhea diseases in Indonesia and to discuss the latest development of sanitation and clean water provision in Indonesia using Indonesia's Socio-Economic Survey (SUSENAS) data for 2011 and 2015. This research uses linear growth method and logistic regression to make projection and analysis. The study finds evidence that poor water and poor sanitation continue to cause diarrhea in Indonesia. We also predict that the Indonesian Government cannot achieve the target of SDG in 2019.
\end{abstract}

\section{KEY WORDS}

Drinking water, sanitation, diarrhea, SDGs, sustainable development.

Indonesia consists of 34 provinces, 416 districts, and 98 cities. For next down level it has 7,094 subs local district that consists of 73,183 villages and 8,412 urban wads (UNICEF, 2016). The astounding number of any nation in the world (India is the biggest). Open defecation heads of districts are directly elected - as a result of Indonesia's "big bang" decentralization that started in the early 2000s.

Every year almost 150 thousand children less than five years old die in Indonesia, in most cases from preventable causes linked to diseases such as diarrhea. More than 50 million Indonesians don't utilize toilets, which is the second most leaves excreta that flies or playing children can bring into the house and it then can contaminate of drinking water with eating utensils or even get consumed directly with food by children who fail to wash their hands properly.

Diarrhea is induced by contagious organisms contains protozoa, bacteria, viruses and helminthes which are transferred from individual stools to mouths of other individuals by the term fecal-oral transmission (Begum et al., 2011). Human waste is a major source of pathogenic diarrhea although animal feces also contain microorganisms that can cause diarrhea. As a result, the disease can be resisted by improving water quality and preventing the digestion of water that comes from infected sources (Briscoe, 1977). Diarrhea can disseminate well form one individual to another.

Diarrhea is the main health issue for the youth children in some developing countries (Begum et al., 2011). Hard infectious diarrhea in children occurs mostly happen under bad environmental sanitation and hygiene condition, deficient water supplies, and poverty (Begum et al., 2011). Childhood diarrhea in industrialized countries is the predominant and high economic cost (Begum et al., 2011). In developed countries, there are many factors such as daycare attendance, contact with symptomatic persons in the home or elsewhere exposure, lack of breastfeeding, and exposure to contaminated food and water childhood diarrhea are related to childhood diarrhea. 
Most of the diarrhea fatality is caused by unimproved water, bad sanitation, and hygiene. Young children from household implementing open defecation in streams or river have diarrhea rates are about 66 percent higher than those in family that has toilet facility and septic tank (UNICEF, 2012). The major pathogenic organisms of diarrhea in many countries transmitted through fecal-oral route (Faechem, 1984). The development in sanitation and water, together with the better living standards, have the main role to cut down diarrhea prevalence and to control typhoid and cholera epidemic in North America and Europe from 1860 until 1920 (Esrey et al., 1985).

Approximately 72 million Indonesians do not get access to adequate drinking water, and around 33 millions of them can only access unimproved water (ANTARA, 2017). Furthermore, 100 million Indonesians lack access to better sanitation facilities. Indonesia medium development term plan (RPJMN) 2015-2019 has included the availability of access to drinking water and proper sanitation for all people or we called as "universal access". According to Indonesia Statistic Office in 2015, the attainment for drinking water is 71 percent and sanitation 62 percent respectively.

Improved water supply access increase 15 percent in over last decade from, with only a small percentage of the population (about 21 percent) get access to piped water facility in 2012 (WHO/UNICEF 2014). Indonesia has already met Millennium Development Goal (MDG) target. Despite the progress during 2009-2012, higher efforts are required to achieve Indonesia government target of 100 percent improved water access by the end of 2019. Most of the progress took place in village areas, where improved water access facilities going up from 61 percent in 1990 to 76 percent in 2012. In urban areas, the progress has been slower.

Equally important is access to improved sanitation. Sanitation is facility and service for safely human disposal and human waste based on WHO definition. Lack of sanitation is the main factor the incidence of illness and improved sanitation are known to give the positive effect on health both at home and in the community. The sanitation term is related to the preservation of the hygienic environment, through activities such as garbage collection and waste water disposal.

Sanitation access in Indonesia has inclined over last decade from 35 percent to 59 percent in 2012 (WHO/UNICEF JMP 2015). Despite low progress in the last two decades, the recent development in improved sanitation access suggests that Indonesia probably meet the SDG target in 2019. One important meaning in Indonesia case is that sanitation includes solid waste, drainage, and water management.

Improved sanitation access and clean water are also included in Sustainable Development Goals (SDG), as declared on 25 September 2015 by United Nations. In particular, the goal is to "providing sustainable management of sanitation and water for all". Some detail points related to this goal are to:

- Accomplish universal access to provide safe drinking water for everybody;

- Accomplish provide fair hygiene and sanitation for all and stop open defecation, giving special awareness for women and girls;

- Develop water quality by eliminating disposal, reducing pollution, release hazardous chemical and materials, increasing recycling and reuse action;

- Improve the effectiveness of water use in all areas and economically guarantee and supply of freshwater to solve lack of water and decrease the quantity of water shortage for individual's experience;

- Broader global participation and limit the number of building to create nations in sanitation and water associated exercises and projects, involve water productivity, water collecting, wastewater treatment, desalination, and reuse innovations;

- Support the enthusiasm of local communities in sanitation and water operation.

We are interested to explore the relationship between sanitation, safe water access and diarrhea in Indonesia. Based on that, we develop the following questions:

- Is Indonesia on the right track to achieve the SDG target in terms of clean water and sanitation?

- Are unimproved sanitation and poor drinking water major causes of diarrhea diseases? 


\section{LITERATURE REVIEW}

The SDGs is a comprehensive and complex global agenda for the world in the future in 2010 (Nicolai et al. 2015). Millennium development goals (MDG)'s objective is development global demonstrative, narrow objective and focuses to developing countries, SDG universally accepted and represent complexity sustainable development in all aspects (Nicolai et al., 2015). Nicolai et al., (2015) make the best available projection to all SDG target progress for some countries, where there are gaps calculated by them. Based their projection, they found the sanitation and clean water target in developing countries is in the right direction, but the growing need to accelerate more of current growth in order to meet the goals. Nicolai et al., (2015) suggest that sanitation and clean water need significant action and innovation.

Many researchers have studied the relationship between sanitation, drinking water and diarrhea. Henry et al., (1990) discuss sanitation condition, infectious food and water, and diarrhea in Bangladesh village. They found that sanitation and sanitation intervention plan had a significant effect on diarrheal morbidity in children aged 6-23 months in also children less than 5 years of age. Another study, Begum et al., (2011) found that improve sanitation and water joint together have strong effects cutting down diarrhea among children under five years old. They suggest creating public policy by supporting private (household) and public investments in sanitation and water to cut down diarrhea case.

Cameron \& Olivia (2011) found that sanitation has developed over the past decade in Indonesia. The Indonesian government had done many approaches to solve the sanitation problem. The top-down approach was initially used, but not very effective with regards to the provision of infrastructure. Community base evolution models were considered to have had more success. A recent study by Patunru (2015) shows that providing sanitation access and decent water source remain important for cutting down the spreading of diarrhea. Furthermore, improving sanitation is relatively of higher urgency than improving water source.

Esrey et al., (1985) observe a favorable effect of good sanitation and water on diarrhea, whereas water quality improvement to be less important than improvements of the available water or excreta disposal. Some studies showed the purpose of controlling diarrhea, cholera and other diseases, the water quality and quantity have important factors (Briscoe, 1977). A number related studies have unsuccessful to find health gain significantly while the water quality was developed alone Wall \& Keeve (1974), Levine et al., (1976), Baltazar et al., (1988), in contrast to those who found health gain significantly of improved water quality (see, for instance Wagner \& Lanoix, (1959)). This is opposite findings that have previously found health gain significantly of the improved water quality that was conducted by (Wagner \& Lanoix, 1959).

In brief, the effectiveness of sanitation and good water supply on diarrhea and other water-associated diseases some developing countries have been expanding discussed and debated among researchers for several decades, Saunders \& Warford (1976), McJunkin (1982), Faechem \& et al., (1983) without reaching a single conclusion.

The previous study explains that the evidence related to the sanitation is not strong evidence World Bank (2006), Pattanayak et al., (2007). The evidence water variable is also found differently: however bad water mostly is the main cause of diarrhea, some seen as the opposition are noticeable findings in some studies exploring this relationship. Esrey et al., (1985) see the effect of better sanitation and water related to diarrhea.

\section{METHODS OF RESEARCH}

In order to answer the first question, we create the projection for Indonesia achievement by using linear growth method. Even though, there is the criticism of this method (for example Osorio (2008); Hailu \& Tsukada (2011), we continue, nevertheless, because the objective is only in getting indicative figures. This method was used by Patunru (2015) to create the projection of Indonesia's development in safe drinking water and sanitation with regards to its MDG target. Patunru (2015) found that Indonesia could achieve 
MDG target in 2015. In line with Patunru (2015), WHO/UNICEF Joint Water Supply and Sanitation Monitoring Programme (2015) drinking water and sanitation report showed that Indonesia has met the MDG target.

Following Patunru (2015) we use the data compiled by WHO and UNICEF. We run linear growth projection to get indicative figures of Indonesia's improved sanitation and water access in 2019. We use 2015 data as it is the base year for the SDG program. We project to the year 2019 as it is the target year that Indonesian government wants to achieve its SDG target. Later, we compare the result with the requirement of SDG itself.

To address the second question, we use a series of logistic regressions, following Patunru (2015). The dependent variable in this study represents whether or not a household member surveyed in the SUSENAS has had diarrhea disease. We assign 1 (one) if the household member suffers diarrhea within last 1 month to the survey and assign 0 (zero) otherwise. Unlike in the previous years' surveys, in the 2015 SUSENAS, there is no single question that specifically asks about diarrhea incidence. Instead, the question bundles diarrhea together with other health complaints ("fever, cough, runny nose, diarrhea, dizziness, chronic illness, and so on"). We are aware, nevertheless that diarrhea still becomes the major disease in Indonesia in 2015, for example, there was 18 extraordinary events diarrhea involving 1,213 people and the death of 30 people (Ministry of Health Indonesia 2015).

The key variables of interest are unimproved sanitation and unimproved drinking water supply facilities. In WHO/UNICEF (2015) report and its JMP Update 2017 website, improved water source is defined as "based on the nature of its construction, enough to protect the source from outside contamination, especially fecal matter" whereas, an improved sanitation is one that "hygiene and free from human contact". By their definition, shared sanitation facility with other households is not considered as "improved". WHO/UNICEF (2014) defines: Unimproved water namely surface water consists of dam, river, channel, ponds, spring, streams, irrigation channel, and 'unimproved sources' consist of unsafe dug well, unsafe spring, small tank, bottled water when in fact 'unimproved sanitation' namely open defecation such as defecate in fields, bushes, forests, beaches, open area of water, or open area or disposed of with solid waste; 'unimproved facility' means not hygienic human excreta area from human contact, including bucket latrines or pit latrines and 'shared facilities' means facilities can be occupied by two or more households.

Some variations in the definition of drinking water and sanitation are found elsewhere. For instance, 'bottled water' in common term is advised unimproved by JMP's meaning, nevertheless, it becomes improved meaning in Indonesia. Because we face different category, we have more attention in the component details of sanitation and water facilities. Based on that we define unimproved water is water that source from unsafe spring, or river, unsafe dug well. 'Unimproved sanitation' is sanitation access or facility besides shared or private toilet facility by means of the final disposal facility and water sealed latrine. Following (Patunru, 2015), we also accommodate different definition in our research. We use 'stricter' definition, 'unimproved water' not only aforesaid definition, but we also add safe dug well, safe spring or pump if they are located in the area within 10 meters away from the septic tank or the final disposal. The stricter definition of 'unimproved sanitation' as the facilities besides only private toilet with the similar definition as previously.

This SUSENAS dataset is multilevel where we have the household in the first cluster, district or city cluster in the second and province in the last. Because of nature of our data, where persons/family units living in a similar range are not autonomous of each other, we utilize logistic regression (Rabe-Hesketh et al., 2005).

There are many other factors that cause people who already use sanitation and improved water to get diarrhea. For instance, people have good water and sanitation facility can be affected by diarrhea because of bad environmental conditions in the neighborhood such as the practice of open defecation. We thus include a variable that represents the percentage of the population doing open defecation in the town where the family unit is found. UNICEF defines open defecation as defecation held in fields, bushes, forests, other open spaces or bodies of water, or disposal of human feces with solid waste. We use 
definition for open defecation as one that includes defecating in bushes, fields, open area of water, forests, beaches or other open area or solid waste disposal.

On the other hand, access to health facilities might reduce diarrhea incidence. Similarly, higher income might help the household to live a better life and hence reduces the possibility of diarrhea. Therefore, following Patunru (2015) and Cameron \& Olivia (2011), access to health facilities can reduce the incidence of diarrhea. Likewise, higher income can help households to live better lives and therefore reduce the likelihood of diarrhea. In line with previous research by Patunru (2015); Cameron \& Olivia, (2011), this study also used control variables for the number of health centers in the district as well as per capita household expenditure (Log Expenditure Households) and added a poverty level variable (Poverty) due to poverty one of the factors of inability of the house ladder to have proper sanitation facilities and access to drinking water. Other control variables include gender (Male) and age (Age), highest education of the head of household (Households Education), urban or rural (Urban) or village location of the household, and the floor structure of the house including those on the ground floor (Earthen Floor) and Percentage Open Defecation.

The level of poverty has a negative and significant influence on the fiscal capacity of a region (Risalam, 2013). This causes local governments with high levels of poverty to find it difficult to provide public goods such as access to drinking water and proper sanitation for the community. Low per capita income relates to the level of poverty in an area (Sari, 2018). In order to meet the first objective, we attempt to track Indonesia's progress in drinking water access and sanitation and make a projection for 2019. We use data that was compiled by WHO and UNICEF. We use data from WHO UNICEF drinking water and sanitation progress report in recent data.

As for the second objective, we use data from the National Socio-Economic Surveys (SUSENAS) operated every two years by Indonesia's Office of Statistics (BPS). This survey involves about 250-300 thousand households' sample or about 1 million representative persons. Here we use the 2011 and 2015 survey and get the new findings. This survey data has limitation problem for making comparisons among countries because every country has different questionnaire survey data so it makes hard to compare the development of any given country.

In this research, we use maximum likelihood estimation model. Maximum likelihood estimation model we use for limited dependent and discrete variable with numerical integration (Rabe-Hesketh et al., 2005).

The simple model includes solitary random part or different intercept between the group of samples and induces dependency in this group. Random effect model (RE) is very useful for panel data or cross-sectional data model that is grouped so the response for similar individual or group is cannot be assumed as independent after conditional for exogenous factor. In cross-sectional assembled, the cluster can be households, geographical entities, or firms. Multilevel suitable model with more than one level grouping. Nested random intercept in individual and firm level later can be used in heterogeneity model that unobserved between firm and individual within firms. The firm random intercept level between individuals within similar individual and firm random intercept level result in additional dependency in observations group in the similar individual. The random coefficient can be involved for heterogeneity model that unobserved in the effect variable within the firm and/or individual.

Based on the characteristic data, we propose the model as follows:

$$
Y=\beta_{o}+\beta_{1} W_{i}+\beta_{2 j} S_{i+} X_{i+} \varepsilon_{i}
$$

Where: $Y$ - variable response for diarrhea in household level; Wi - unimproved water in household level; $S_{i}$ - unimproved sanitation in household level; $X_{i}$ - control variables; $\varepsilon_{i}$ - error terms.

Testing of the model is done to ensure that the model is suitable and able to represent existing data. Testing using AIC and BIC because the sample data in the study is very large above 900,000 samples so that if using McFadden R2 it will get a small value which may not 
reflect the suitability of the model. AIC and BIC for 2011 amounted to 0.129 and $-1.236 \mathrm{e}+$ 07 . Whereas for $2015 \mathrm{AIC}$ and $\mathrm{BIC}$ are 0.158 and $-1.23 \mathrm{e}+07$, the smaller the AIC and BIC the better the research model (Suwardi, 2011). Testing for logit models with sensitivity and specitivity to get a good model (Suwardi, 2011). Results obtained correctly (correctly classified) above $98 \%$ for 2011 and 2015 . Based on the test stated that the model is able to state correctly above $98 \%$

\section{RESULTS OF STUDY}

Table 1 shows the progress of the percentage of sanitation and drinking water in Indonesia as compared to its SDG targets. Indonesia wants to achieve 'universal access' in 2019. However, as the table shows, Indonesia is not on track to achieve it. Indonesia should take more action to accelerate the percentage of sanitation and safe drinking water. Indonesia Government target for universal access to provide improved sanitation and water facility for all and reduce the number of unimproved water and sanitation until zero percent by the end 2019 (PAMSIMAS, 2015), similar with SDG target but the difference only the period. The SDG target by in the end 2030 , provide equitable access to safe universally and affordable drinking water for all.

Table 1 - Unimproved Water and Sanitation Access

\begin{tabular}{|c|c|c|c|c|c|c|c|c|}
\hline & $\begin{array}{c}\text { Population } \\
\text { (million), 2010) }\end{array}$ & $\begin{array}{c}1990 \\
(\%) \\
\end{array}$ & $\begin{array}{c}2012 \\
(\%) \\
\end{array}$ & $\begin{array}{c}2015 \\
(\%) \\
\end{array}$ & $\begin{array}{c}2019 \# \\
\%\end{array}$ & $\begin{array}{c}\text { SDGs } \\
\text { Target (\%) }\end{array}$ & $\begin{array}{c}\text { Difference } \\
\text { (percentage points) }\end{array}$ & Status \\
\hline \multicolumn{9}{|c|}{ Water: percentage of population: unimproved drinking water sources } \\
\hline Indonesia & 240 & 30 & 15 & 13 & 10.40 & 0 & -10.40 & not on track \\
\hline Rural & 121 & 39 & 24 & 21 & 17.8 & 0 & -17.8 & not on track \\
\hline Urban & 120 & 10 & 7 & 6 & 5.2 & 0 & -5.2 & not on track \\
\hline \multicolumn{9}{|c|}{ Sanitation: percentage of population: unimproved sanitation } \\
\hline Indonesia & 240 & 65 & 41 & 39 & 34.03 & 0 & -34.03 & not on track \\
\hline Rural & 121 & 76 & 54 & 53 & 48.14 & 0 & -48.14 & not on track \\
\hline Urban & 120 & 39 & 29 & 28 & 25.63 & 0 & -25.63 & not on track \\
\hline
\end{tabular}

Note: (\#) Based on the growth rate of 1990-2015; SDGs Target.

Source: WHO/UNICEF (2015), author calculation.

Table 2 - Descriptive Statistic Variables

\begin{tabular}{|c|c|c|c|c|}
\hline \multirow{2}{*}{ Variable } & \multicolumn{2}{|c|}{2011} & \multicolumn{2}{|c|}{2015} \\
\hline & Mean & Stdev & Mean & Stdev \\
\hline \multicolumn{5}{|c|}{ Response Variable } \\
\hline Diarrhea & 0.015 & 0.12 & 0.16 & 0.23 \\
\hline \multicolumn{5}{|c|}{ Independent Variable } \\
\hline Unimproved Water & 0.19 & 0.39 & 0.15 & 0.35 \\
\hline Unimproved Sanitation & 0.25 & 0.43 & 0.03 & 0.17 \\
\hline Unimproved Water strict & 0.19 & 0.39 & 0.15 & 0.35 \\
\hline Unimproved Sanitation strict & 0.35 & 0.48 & 0.12 & 0.33 \\
\hline \multicolumn{5}{|c|}{ Control Variable } \\
\hline Male & 0.50 & 0.50 & 0.50 & 0.50 \\
\hline Urban & 0.41 & 0.49 & 0.43 & 0.49 \\
\hline Earthen Floor & 0.08 & 0.27 & 0.06 & 0.25 \\
\hline Age & 28.76 & 19.78 & 30.00 & 20.02 \\
\hline $\mathrm{HH}$ Head Education & 3.99 & 3.64 & 5.96 & 3.29 \\
\hline Log expenditure $\mathrm{HH}$ & 13.17 & 0.32 & 13.44 & 0.33 \\
\hline Pct Open Defecation & 0.26 & 0.44 & 0.27 & 0.45 \\
\hline Health Centre & 71.29 & 39.71 & 21.53 & 13.87 \\
\hline Poverty & 13.93 & 8.10 & 12.15 & 7.19 \\
\hline
\end{tabular}

The table implies that sanitation access should be of higher priority than drinking water access as the government has to reduce the 34 percent unimproved sanitation rate, as compared to the 10 percent unimproved water rate at the national level. For the second objective, we summarize the descriptive statistics in Table 2. The average diarrhea prevalence in 2011 was only 0.015 but in 2015 it has increased to 0.016 in household level. It 
means that in the average number of diarrhea case is $1.5 \%$ in 2011 ; this rate has the smaller increase in 2015. Recall, however, that in the 2015 SUSENAS, the question bundled diarrhea with fever, cough, and other health problems. The table also shows that in contrast to the increase in diarrhea prevalence, exposure to bad water and environmental sanitation during the period.

Moving to the next question of whether or not unimproved water and/or unimproved sanitation contribute to increase in diarrheal incidence, Tables 3 and 4 summarize the results for the year 2011 and 2015, respectively. In both years we use the more common definitions of unimproved water and sanitation (denoted "standard model") as well as the stricter definitions (denoted "strict model").

Table 3 - Results of Logistic Regression Analysis Year 2011

\begin{tabular}{|c|c|c|c|}
\hline Model & Coefficients & Odds Ratio & Confidence Interval \\
\hline \multicolumn{4}{|c|}{ Model I (Standard) } \\
\hline Unimproved water & $0.058^{\star \star}$ & 1.060 & $(1.008,1.114)$ \\
\hline Unimproved Sanitation & $0.139^{\star \star *}$ & 1.149 & $(1.079,1.222)$ \\
\hline \multicolumn{4}{|c|}{ Model II (Strict) } \\
\hline Unimproved water strict & $0.052^{* *}$ & 1.053 & $(1.002,1.107)$ \\
\hline Unimproved Sanitation strict & $0.215^{\star \star *}$ & 1.239 & $(1.179,1.304)$ \\
\hline
\end{tabular}

Table 4 - Results of Logistic Regression Analysis Year 2015

\begin{tabular}{|c|c|c|c|}
\hline Model & Coefficients & Odds Ratio & Confidence Interval \\
\hline \multicolumn{4}{|c|}{ Model I (Standard) } \\
\hline Unimproved water & $0.053^{\star *}$ & 1.055 & $(1.003,1.109)$ \\
\hline Unimproved Sanitation & 0.069 & 1.072 & $(0.975,1.179)$ \\
\hline & Model II (Strict) & $(1.004,1.109)$ \\
\hline Unimproved water strict & $0.054^{\star *}$ & 1.056 & $(0.969,1.075)$ \\
\hline Unimproved Sanitation strict & 0.021 & 1.021 & \\
\hline
\end{tabular}

Table 5 - Results of Logistic Regression Analysis Year 2011 for Control Variable

\begin{tabular}{|c|c|c|c|}
\hline & Coefficients & Odds Ratio & Confidence Interval \\
\hline Model & \multicolumn{2}{|c|}{ Model I (Standard) } & $(-0.006,0.0702)$ \\
\hline Male & 0.0324 & 1.033 & $(-0.196,-0.1054)$ \\
\hline Urban & $-0.1509^{* * *}$ & 0.860 & $(0.0271,0.1646)$ \\
\hline Earthen Floor & $0.0959^{* * *}$ & 1.101 & $(0.0113,0.1337)$ \\
\hline Age & $0.0124^{* *}$ & 1.012 & $(-0.041,-0,029)$ \\
\hline HH Education & $-0.0348^{* * *}$ & 0.966 & $(-0.0005,0.0005)$ \\
\hline Pct Open Defecation & $0.0831^{* * *}$ & 1.087 & $(0.0114,0.0171)$ \\
\hline Health Centre & 0.0001 & 1.000 & $(0.1515,0.3065)$ \\
\hline Poverty & $0.0143^{* * *}$ & 1.014 & $(-0.006,0.0695)$ \\
\hline Ln Expenditure & $0.2290^{* * *}$ & 1.257 & $(-0.195,-0.104)$ \\
\hline Model II (Strict) & & & $(0.0151,0.1526)$ \\
\hline Male & 0.0316 & 1.032 & $(0.0115,0.0135)$ \\
\hline Urban & $-0.1498^{* * *}$ & 0.861 & $(-0.040,-0.027)$ \\
\hline Earthen Floor & $0.0838^{*}$ & 1.087 & $(-0.008,0.0983)$ \\
\hline Age & $0.0125^{* * *}$ & 1.013 & $(-0.0005 ; 0.0005)$ \\
\hline HH Education & $-0.0335^{* * *}$ & 0.967 & $(0.0112,0.0170)$ \\
\hline Pct Open Defecation & 0.0450 & 1.046 & $(0.1526 ; 0.3074)$ \\
\hline Health Centre & $3.5500^{* *}$ & 1.000 & \\
\hline Poverty & 0.0141 & 1.014 & 1.259 \\
\hline Ln Expenditure & 0.2300 & & \\
\hline
\end{tabular}

Table 3 implies that in 2011, a person living in an environment with poor environmental sanitation will have a risk of developing diarrheal diseases about 1.2 times compared to those living in a place with good environmental sanitation. Table 4 shows that in 2015 this likelihood decreases slightly to 1-1.1 times. In terms of water, both tables show that households with unimproved water are only slightly prone to diarrhea disease compared to those with improved water. These imply that, firstly, increased access to improved sanitation 
and improved water may help reduce the incidence of diarrhea. Secondly, the effect of unimproved sanitation seems bigger than unimproved water. Thirdly, the government made good progress in providing better good water and sanitation facility during 2011-2015. This is consistent with Joint Monitoring Programme (JMP) reports that Indonesia has made a moderate progress in improving its sanitation and water supply (WHO/UNICEF JMP Programme 2015). The results are also consistent with Begum et al., (2011) found both good sanitation and water access have significant effect reduces the prevalence of diarrhea for children under five years old. In addition, Baltazar et al., (1988) found improved sanitation reduced diarrheal incidence in Malawi, consistent with the fact that we find the bigger effect from unimproved sanitation relative to unimproved water.

Based on Table 5 for the standard model we can see that people living in urban areas are less at risk of developing diarrhea compared to people living in rural areas. In 2011, people who lived on the ground floor were more at risk of developing diarrhea 1.1 times than people living in rural areas. Respondents who have an older age have a risk of getting diarrhea once more than those who are younger. Education has a negative relationship with the chances of developing diarrhea. Based on Table 5 with the standard model, heads of households who have higher education have a risk of developing diarrhea one time smaller than those with low education.

The habit of defecating in open spaces has a risk of developing diarrhea one time greater than the one who defecates in a place with proper sanitation facilities. Poverty rates have a positive relationship with the chance of diarrheal diseases. Based on table 5.5 the standard model for 2011. Poor people have a one-time chance of experiencing diarrheal pain compared to people who are not poor. For per capita income factors have a negative relationship where people who have greater per capita income, the chance of experiencing diarrheal disease is 1.2 times smaller than people who have small per capita income.

Table 6 - Results of Logistic Regression Analysis Year 2015 for Control Variable

\begin{tabular}{|c|c|c|c|}
\hline Model & Coefficients & Odds Ratio & Confidence Interval \\
\hline Male & \multicolumn{2}{|c|}{ Model I (Standard) } & $(-0.060,0.0070)$ \\
\hline Urban & -0.0266 & 0.974 & $(-0.026,0.0522)$ \\
\hline Earthen Floor & 0.0130 & 1.013 & $(-0.602,0.0777)$ \\
\hline Age & 0.0088 & 1.009 & $(-0.002,-0.0003)$ \\
\hline HH Education & $-0.0013^{* *}$ & 0.999 & $(-0.0680,0.0109)$ \\
\hline Pct Open Defecation & $0.0056^{*}$ & 1.006 & $(-0.003,-0.0005)$ \\
\hline Health Centre & -0.0291 & 0.971 & $(0.004,0.010)$ \\
\hline Poverty & $-0.0017^{* *}$ & 0.998 & $(-0.2070,-0.075)$ \\
\hline Ln Expenditure & $0.0068^{* *}$ & 1.007 & $(-0.060,0.0070)$ \\
\hline Model II (Strict) & $-0.1412^{* * *}$ & 0.868 & $(-0.060,0.0070)$ \\
\hline Male & & & $(-0.060,0.0782)$ \\
\hline Urban & -0.0266 & 0.974 & $(-0.002,-0.0003)$ \\
\hline Earthen Floor & 0.0123 & 1.012 & $(0.0002,0.0109)$ \\
\hline Age & 0.0093 & 1.009 & $(-0.067,0.0112)$ \\
\hline HH Education & $-0.0013^{* *}$ & 0.999 & $(-0.003,-0.0005)$ \\
\hline Pct Open Defecation & $0.0056^{*}$ & 1.006 & $(0.0039,0.0097)$ \\
\hline Health Centre & -0.0277 & 0.973 & $(-0.207,-0.075)$ \\
\hline Poverty & $-0.0018^{* *}$ & 0.998 & \\
\hline Ln Expenditure & $0.0068^{* * *}$ & 1.007 & 0.868 \\
\hline
\end{tabular}

Based on table 6 for the 2015 standard model there are several meanings. First, women have the opportunity to experience diarrhea more than once when compared to men. Both age factors still have a positive relationship with the number of diarrheal diseases, the higher the age, the higher the risk of developing diarrhea. In 2015, the number of health centers in a region had a negative relationship. The greater the number of hospitals or the availability of Puskesmas, the risk of getting diarrhea is smaller one time than in regions without or with a smaller number of Puskesmas. Poverty in 2015 still has a positive relationship with the number of cases of diarrhea. The poorer in an area the greater the 
chance that the area will suffer from diarrhea. Per capita income also still has a negative relationship with the chance of developing diarrhea.

Respondents' economic factors are factors that influence the emergence of diarrheal disease in Indonesia, this is evidenced by the variable poverty or poverty rate and income per capita of the Indonesian population.

\section{DISCUSSION OF RESULTS}

The Government has targeted that by 2019 every Indonesian should have access to $100 \%$ viable sanitation. To achieve the $100 \%$ target, the sanitation service approach will be done through local system services and centralized systems with community-based and institutional approaches. Indonesia administration structure that divides in some level government starts from the rural area until province level which has different characteristic. This condition has become a challenge for the government to control and accommodate many plans. The duration project is still too short period in order to achieve. The government can evaluate this project whether to reduce the target or extend the period. Diarrhea still becomes the major disease in Indonesia. The government has implemented many policies to cut down the prevalence of this disease. The progress and policy related to diarrhea are fairly good from year to year.

\section{CONCLUSION}

Unimproved sanitation and unimproved water still contribute to diarrhea disease in Indonesia. However, there are many other factors that jointly affect the incidence of diarrhea case. In our model gender, head household education, open defecation practices, earthen floor, household expenditure and poverty are some factors that also affect the incidence of diarrhea in Indonesia.

It is possible if people living in areas with poor sanitation and clean water can more possibility to get diarrhea because the organism that causes the incidence of diarrhea live in the dirty or bad environment. This organism common transmitted through fecal-oral route (Faechem 1984). As a result, people live in bad sanitation and water access environment have higher possibility to get diarrhea rather than people who live in the good environment.

\section{SUGGESTIONS}

Indonesia has made innovation and extra action in order to meet its universal access target in 2019. The precise time for which the universal access target is met may still need to be evaluated. For example, firstly, Indonesia government should make a community-based program in some selected areas that support for society by giving them training and facilities to establish clean water and good sanitation. If this program can work well and sustainable in these selected areas, the government can replicate this program at a national scale. Secondly, Indonesia government can attract the private sector to help provide sanitation and safe drinking water infrastructure in some remote areas. Thirdly, Indonesia government can make early childhood education program for universal access. This program gives young children basic knowledge in safe water and sanitation knowledge.

\section{REFERENCES}

1. ANTARA (2017). 'Bappenas tekankan pentingnya akses air minum dan sanitasi'.Accessed on 20 November 2017, from http://www.antaranews.com/

2. Baltazar, J., Briscoe, J., Mesola, V., Moe, C., Solon, F., Vanderslice, J., \& Young, B. (1988). Can the case-control method be used to assess the impact of water supply and sanitation on diarrhoea? A study in the Philippines. Bulletin of the World Health Organization, 66(5), 627. 
3. Begum, S, Ahmed, M, \& Sen, B (2011). 'Do Water and Sanitation Interventions Reduce Childhood Diarrhoea? New Evidence from Bangladesh', The Bangladesh Development Studies, 1-30.

4. Briscoe, J (1977). 'The Role of Water Supply in Improving Health in Poor Countries with special reference to Bangladesh', Scientific Report No.6 Cholera Research Laboratory, Dacca, Bangladesh.

5. Cameron, L \& Olivia, S (2011). 'Sanitation and Health: The Past, The Future and Working Out What Works. In Manning C, Sumarto S (eds) Employment, Living Standards' and Poverty in Contemporary Indonesia', Institute of Southeast Asian Studies, Singapore, 245-69.

6. Esrey, SA, Faechem, RG, \& Hughes, JM (1985). 'Intervention for the Control of Diarrhoeal Diseases among Young Children: Improving Water Supplies and Escreta Disposal Facilities', Bulletin of the World Health Organization, 63, 4, 757-772.

7. Faechem, RG (1984). 'Interventions for the Control of Diarrhoeal Diseases among Young Children: Promotion of Personal and Domestic Hygiene', Bulletin of the World Health Organization, 62, 467-476.

8. Faechem, RG \& et al. (1983). 'Sanitation and Disease: Health Aspects of Excreta and Wastewater Management, Chistester', John Wiley.

9. Hailu, D \& Tsukada, R (2011). Achieving the Millennium Development Goals: a measure of progress, Working Paper, International Policy Centre for Inclusive Growth, Accessed 30 August 2017 from https://www.econstor.eu/handle/10419/71790.

10. Henry, FJ et al. (1990). 'Environmental sanitation, food and water contamination and diarrhoea in rural Bangladesh', Epidemiology \& Infection, 104, 2, 253-259.

11. Indonesia, KK (2015). 'Profil kesehatan Indonesia tahun 2011'.

12. Levine, R., D'Souza, S., Khan, M., \& Nalin, D. (1976). Failure of sanitary wells to protect against cholera and other diarrhoeas in Bangladesh. The Lancet, 308(7976), 86-89.

13. McJunkin, FE (1982). 'Water and Human Health, National Demonstration Water Project', USAID, Washington DC.

14. Nicolai, $S$ et al. (2015). 'Projecting progress reaching the SDGs by 2030', Overseas Development Institute (ODI).

15. Osorio, R 2008, 'Alternatives for Projecting MDGs Indicators. Technical Papers 2. Brasilia', International Policy Center for Inclusive Growth.

16. PAMSIMAS (2015). 'Agenda Nasional Pembangunan Air Minum dan Sanitasi', Accessed 20 November 2017 from http://new.pamsimas.org/

17. Pattanayak, S. K., Poulos, C., Wendland, K. M., Patil, S. R., Yang, J. C., Kwok, R. K., \& Corey, C. G. (2007). Informing the water and sanitation sector policy: case study of an impact evaluation study of water supply, sanitation and hygiene interventions in rural Maharashtra, India. RTI International, 1-30.

18. Patunru, AA (2015). 'Access to Safe Drinking Water and Sanitation in Indonesia: Water and sanitation in Indonesia', Asia \& the Pacific Policy Studies, 2, 2, 234-244.

19. Rabe-Hesketh, S, Skrondal, A, \& Pickles, A (2005). 'Maximum likelihood estimation of limited and discrete dependent variable models with nested random effects', Journal of Econometrics, vol. 128, no. 2, pp. 301-323.

20. Risalam, F (2013). 'Analisis Tingkat Kemiskinan, Ketersediaan Infrastruktur Sekolah, Dan Pertumbuhan Ekonomi Terhadap Kemandirian Fiskal Di Kabupaten/Kota Provinsi Jawa Tengah Periode 2007-2011', Economics Development Analysis Journal, 3, 2, 12.

21. Sari, NI (2018). 'Determinan Tingkat Kemiskinan di Daerah Istimewa Yogyakarta Tahun 2007 - 2014', Economics Development Analysis Journal, 2, 7, 9.

22. Saunders, RJ \& Warford, JJ. (1976). 'Village Water Supply: Economics and Policy in Developing World. Baltimore', Johns Hopkins University Press.

23. Suwardi, A (2011). Modul STATA: LPM, LOGIT dan PROBIT MODEL Edisi 2011, Laboratorium Komputasi Departemen IImu Ekonomi FEUI.

24. UNICEF (2012). 'Issue Brief: Water, sanitation \& hygiene', UNICEF INDONESIA.

25. UNICEF (2016). 'Equity in Public Financing of Water, Sanitation and Hygiene (WASH) Indonesia'. 
26. Wagner, EG \& Lanoix, JN (1959). 'Water Supply for Rural Areas and Small Communities. Geneva', WHO.

27. Wall, JW \& Keeve (1974). 'Water Supply, Diarrhoeal Disease and Nutrition: A Survey of the Literature and Recommendation for Research', Water Supply project Division, International Bank for Reconstruction and Development.

28. WHO/UNICEF (2014). 'Progress on Drinking Water and Sanitation 2014 Update'.

29. WHO/UNICEF Joint Water Supply and Sanitation Monitoring Programme, World Health Organization, \& UNICEF 2015, Progress on sanitation and drinking water.

30. World Bank (2006). 'A guide to Water and Sanitation Sector Impact Evaluation, Impact Evaluation No.4 Poverty Reduction and Economic Management'. 